\title{
ENSINAGENS E APRENDIZAGENS DOS SABERES-FAZERES TRADICIONAIS: UMA EDUCAÇÃO INFORMAL DO CAMPO.
} Sergio Ricardo Pereira CARDOSO ${ }^{1}$

\begin{abstract}
RESUMO: Este texto tem a ambição de traçar relações entre os saberes-fazeres tradicionais e a educação informal do campo, articulando educação e cultura na construção e reconstrução contínua dos saberes-fazeres tradicionais por meio das relações cotidianas, bem como a maneira como se dá a socialização de tais saberes-fazeres. A área de estudo localiza-se na Reserva Extrativista Marinha Caeté-Taperaçu, sendo a metodologia empregada a etnoecologia. Os dados coletados em pesquisas diversas demonstram que os saberes-fazeres são produzidos e socializados em espaços diversos, indo desde os espaços familiares aos espaços comunitários. As ensinagens e aprendizagens são protagonizadas pela oralidade, pela observação e a própria prática do saber-fazer, aprende-se e ensina-se fazendo. Assim como os saberesfazeres sofrem mudanças, as estratégias de ensinagens e aprendizagens também acompanham tais transformações, principalmente devido às novas tecnologias, que influenciam a inserção de novas maneiras de fazer, ou seja, novos saberes; dinamizam, portanto, a cultura através dessa educação informal do campo.
\end{abstract}

PALAVRAS-CHAVE: Educação informal; Saberes-fazeres tradicionais; RESEX Marinha Caeté-Taperaçu.

\begin{abstract}
This text has the ambition to trace relationships between traditional Knowledge and practices and rural Informal Education, providing the linking of education and culture in the development and continuous reconstruction of Knowledge and practices traditional through everyday relationships, and the way of socialization of these. The study area is located in the Marine Extractive Reserve Caeté-Taperaçu, and having as methodology the ethnoecology. The data collected in various research shows that the traditional Knowledge and practices are produced and socialized in several spaces, ranging from the familiar spaces to community spaces. The teaching strategies and learning are led by orality, by observation and own practice of knowledge and actions, learn and teach through practice. As the traditional Knowledge and practices suffer changes, the teaching strategies and learning also accompany such changes, mainly due to new technologies, influencing the inclusion of new ways of doing, and therefore new knowledge; transforming thus the culture through rural informal education.
\end{abstract}

KEYWORDS: Informal education; Traditional Knowledge and practices; Marine Extractive Reserve Caeté-Taperaçu.

\section{CONSIDERAÇÕES INICIAIS}

As categorias "educação informal", "ensinagens" e "aprendizagens", bem como suas relações com os saberes tradicionais e, por conseguinte, uma educação informal do campo, são fundamentais para o desenvolvimento deste texto.

É frequente o uso dos termos "educação formal", "educação informal” e "educação nãoformal" quando se fala das modalidades da educação (LIBÂNEO, 2007); entretanto, há uma certa confusão entre tais conceitos.

De um lado, temos a educação informal, que são as ensinagens e aprendizagens assistemáticas, espontâneas, sem necessariamente uma intencionalidade nem uma organização propriamente dita, isto é, consiste na introspecção do mundo, não precisando de uma instituição

\footnotetext{
${ }^{1}$ Professor Doutor; Coordenador / Professor do Programa de Pós-Graduação Lato Sensu em Ciências Ambientais e Desenvolvimento Sustentável da Amazônia; Instituto Federal de Educação, Ciência e Tecnologia do Pará (IFPA) Campus Bragança; e-mail: sergio.ricardo@ifpa.edu.br .
} 
formalizada para isso. Esse tipo de educação se processa nas experiências vivenciadas no cotidiano, sem uma intencionalidade explícita, resultando, portanto,

do "clima" em que os indivíduos vivem, envolvendo tudo o que do ambiente e das relações socioculturais e políticas impregnam a vida individual e grupal. Tais fatores ou elementos informais da vida social afetam e influenciam a educação das pessoas de modo necessário e inevitável, porém não atuam deliberadamente, metodicamente, pois não há objetivos preestabelecidos conscientemente. Daí seu caráter não-intencional (LIBÂNEO, 2007, p. 90).

De outro, situa-se a educação "organizada e sistemática", que se enquadram nas tipologias "educação formal" e "educação não-formal". A "educação formal" geralmente está ligada ao poder público estatal, implicando em regras como frequência obrigatória, expedição de diplomas, sistemas de avaliação, ou seja, "depende de uma diretriz educacional centralizada como o currículo, com estruturas hierárquicas e burocráticas, determinadas em nível nacional, com órgãos fiscalizadores dos ministérios da educação" (GADOTTI, 2005, p. 02).

Já a "educação não-formal" traduz-se como concepção e demanda educativa com o propósito de superar as deficiências, incompletudes e incapacidades do sistema formal de ensino. Para Cury (1995, p. 105),

a educação não-formal é aquela que se pode definir educativamente em projetos de outras áreas [...] em confronto com a educação formal, ela possui uma elasticidade muito grande dado o seu distanciamento em relação às regras burocráticas da sociedade política. Nessa distinção, a educação não-formal inclui, sem dúvida, os meios de comunicação de massa, os projetos de saúde e higienes públicas, a publicidade oficial ou não, os grupos da sociedade civil que se reúnem com finalidades comuns e específicas.

O termo "ensinagem", segundo Polity (2002, p. 30), se traduz numa base relacional na medida em que pressupõe-se que o conhecimento é construído na e pela relação com o outro, agregando valor à novas experiências; o educador seria, no processo de ensino e aprendizagem, uma pessoa mais experiente que saberia relacionar os saberes com os fazeres na vida real e cotidiana, com isso, fomentaria mais facilmente a reflexão e/ou assimilação. Ou seja, o educador, consciente ou não, estaria de posse dos conhecimentos científicos e/ou tradicionais, sendo que lhe é esperado saber reconstruí-los com os outros.

Já a categoria "aprendizagem" é entendida aqui como aprendizagem não formal, ou seja, aquela que se desenvolve mediante os desejos e necessidades práticas do indivíduo. Afinal,

O conceito de aprendizagem emergiu das investigações empiristas em Psicologia, ou seja, de investigações levadas a termo com base no pressuposto de que todo conhecimento provém da experiência. Isso significa afirmar o primado absoluto do objeto e considerar o 
sujeito como uma tábula rasa, uma cera mole, cujas impressões do mundo, formadas pelos órgãos dos sentidos, são associadas umas às outras, dando lugar ao conhecimento. $\mathrm{O}$ conhecimento é, portanto, uma cadeia de ideias atomisticamente formada a partir do registro dos fatos e se reduz a uma simples cópia do real (GIUSTA, 1985, p. 26).

Partindo, então, da discussão conceitual supracitada, é possível defender a tese de que os saberes tradicionais das comunidades rurais, ribeirinhas, pertencentes às Reservas Extrativistas, entre outras territorialidades em que o ser humano extrai sua vivência da natureza, se processam numa educação informal do campo.

Sendo assim, o objetivo deste texto é demonstrar que a rotina das populações pertencentes à Reserva Extrativista (RESEX) Marinha Caeté-Taperaçu se materializa numa educação informal do e no campo, tendo papel fundamental na construção e reconstrução dos diversos processos de ensinagens e aprendizagens de seus saberes-fazeres.

\section{O LóCUS}

O Estado do Pará abrange uma área de 1.247.954.666 km², ocupando o leste da Amazônia brasileira, onde se encontra o município de Bragança, localizado a $1^{\circ} 03^{\prime} 18^{\prime}$ ' $\mathrm{S}$ e $46^{\circ} 45^{\prime} 55^{\prime}$ ' W a uma altitude de 29m, o clima é úmido, megatérmico, do tipo Ami (KATO, 1992). Situado na mesorregião do nordeste paraense, conhecida como microrregião bragantina, possuindo uma extensão territorial de 2.091,930 km², com uma população estimada de acordo com o senso 2010 de 113.227 habitantes e densidade demográfica de 54,13 hab/km² (IBGE, 2010).

A cidade faz fronteira ao norte com o Oceano Atlântico, sul com os municípios Santa Luzia do Pará e Viseu, leste com o município Augusto Corrêa e Oeste com o município Tracuateua. Sendo cercada por manguezais, quase que totalmente, possuindo igarapés em seu entorno (SOUSA JÚNIOR, 2010). A maioria das pessoas que vive na área rural, encontra-se em expansão na direção da rodovia PA-458 e BR-316, tanto no sentido de Tracuateua, quanto no sentido de Augusto Corrêa. (SANTOS \& SOUSA JÚNIOR, 2012).

O processo de ocupação rural da região bragantina deu-se com a chegada dos nordestinos que estavam procurando melhores condições de trabalho e se refugiando da seca no nordeste; o Estado, então, tentou organizar este processo por meio da criação de colônias agrícolas. A ocupação desenvolvida foi intensiva, passando esta microrregião, conjuntamente com a de Guajarina e a do Salgado, a formar a região nordeste paraense e uma das zonas de maior densidade demográfica do Estado (HEBETTE, 1986). 
A essas questões, não se pode esquecer o fato dessa região possuir um dos principais ecossistemas do nordeste paraense, constituindo-se em fontes de recursos naturais para muitas pessoas que habitam as comunidades rurais daquela região; como exemplo, é possível citar crustáceos, peixes, moluscos, aves, madeira, frutas (açaí, buriti, manga, bacuri, etc.), entre outros. Esta abundância de recursos fornece alimentos à população da referida região desde os tempos mais remotos, como bem comprovam os sambaquis encontrados nas proximidades de algumas destas regiões, que ilustram bem a dieta alimentar de seus habitantes: caranguejos, ostras, mexilhões, siris, peixes, etc.

A ilustração a seguir (Figura 1) dá uma ideia mais concreta da localização da área de estudo da pesquisa:
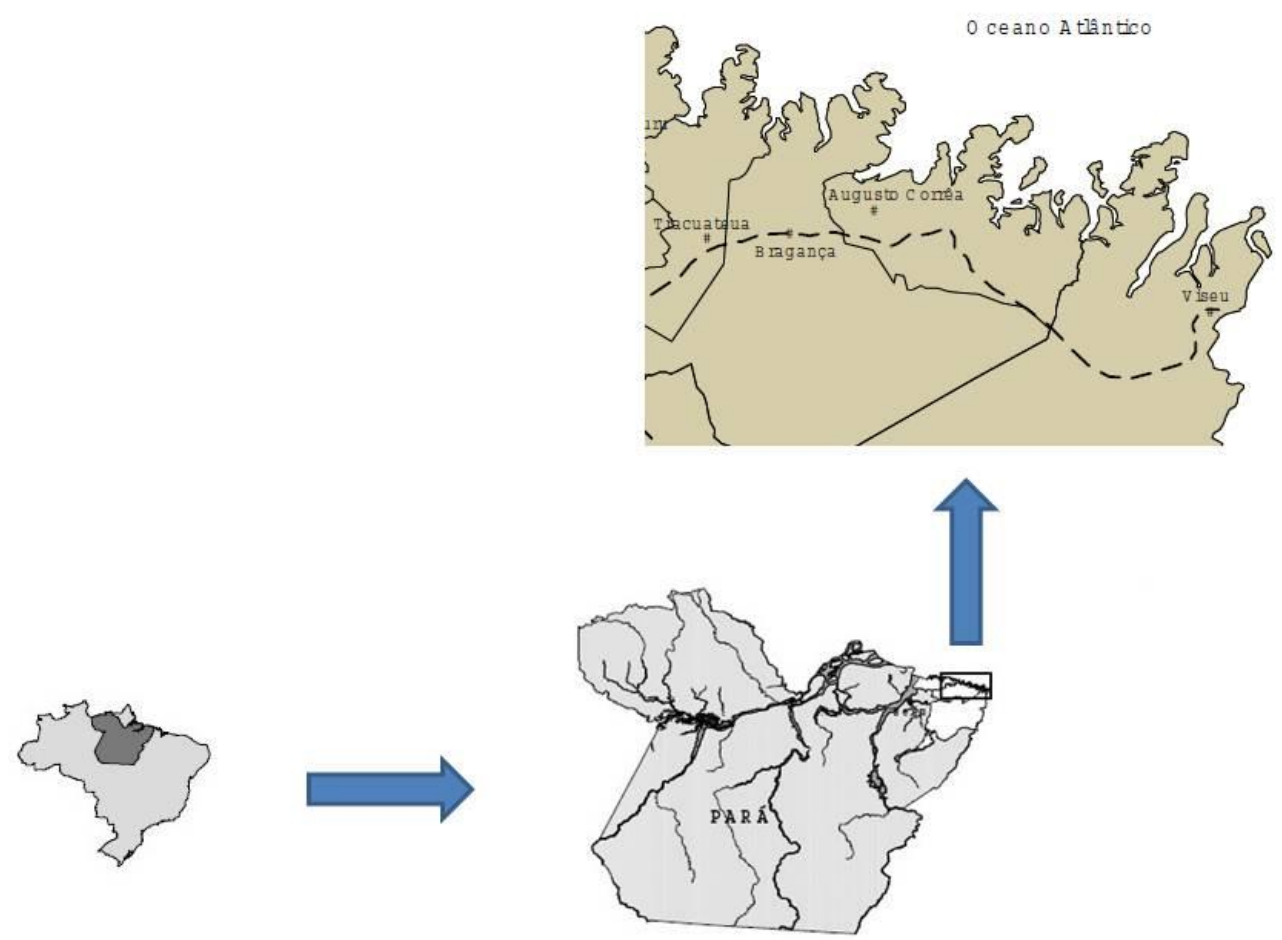

Figura 1: Mesorregião do Nordeste Paraense, destacando a Zona Bragantina, também chamada de Amazônia Atlântica

Fonte: SANTOS, Rita de Cássia P. dos; LISBOA, Regina C. L. MUSGOS (BRYOPHYTA) DO NORDESTE PARAENSE, BRASIL- 1. ZONA BRAGANTINA, MICRORREGIÃO DO SALGADO E MUNICÍPIO DE VISEU. In: ACTA AMAZÔNICA 33(3): 415-422. Disponível em <http://www.scielo.br/pdf/aa/v33n3/v33n3a07>. Acessado em 02/02/2016. 
Vale ressaltar, também, que, a partir da década de 1980, com a abertura democrática, ocorreram mudanças significativas na identidade social hegemônica das comunidades rurais extrativistas, culminando na conquista de leis que favoreceram as comunidades tradicionais, povos indígenas, quilombolas, entre outros. No processar desse movimento, destaca-se a criação das primeiras Reservas Extrativistas (RESEX) em 1990, muito em decorrência das lutas do movimento dos seringueiros na década de 1980.

A RESEX Caeté-Taperaçu, mais especificamente, foi consequência da união da população rural costeira da península bragantina com o objetivo de amenizar a pesca e a extração predatória de crustáceos, principalmente a expansão desenfreada da carnicicultura (MMA, 2006). Somando-se isso à derrubada indiscriminada da mata nativa, em 1998, surgiram os primeiros movimentos para sua criação, intensificando no ano de 1999 até a homologação, em 20 de maio de 2005, do Decreto de Criação da Reserva (BRASIL, 2005).

Mesmo sabendo-se da importância dos agricultores e extrativistas nessa região, percebe-se sua condição econômica de marginalização, pois são consideravelmente pobres, sendo frequentemente categorizados "preguiçosos", "analfabetos" e "ignorantes", ou seja, muitas vezes nem são reconhecidos pelos próprios produtores rurais mais abastados. Boa parte dessa visão se dá pela não inserção destes agricultores / extrativistas na lógica capitalista desumanizante e depredadora da natureza; é de se pensar: existe vida mais sustentável do que a de um agricultor / extrativista, que vive em harmonia com os ciclos da natureza?

Apesar dessas condições, eles sobrevivem à intensa penúria, provocada pela constante degradação dos sistemas ecológicos de coleta e pela falta de políticas públicas que lhes garantam uma certa estabilidade econômica. Não há, nestas comunidades, uma delimitação clara entre agricultores e extrativista; pois, os extrativistas sempre complementam suas rendas com agricultura de pequeno porte ou com a chamada pesca pequena (artesanal de pequena escala). Tal situação os deixa à margem de muitas organizações rurais, pois não são considerados pescadores nem agricultores, o que dificulta o cadastro em tais organizações, a exemplo de outras regiões do Brasil (IBAMA, 1994).

Dessa maneira, os extrativistas / agricultores de pequeno porte não são reconhecidos pelo seu trabalho, tanto na esfera econômica e social como na esfera política, já que seus saberes-fazeres são ignorados pelo poder público como importantes na conservação dos ecossistemas nas regiões de mangue. A consequência dessa postura política é a ausência de participação desta parcela da 
população na formulação de políticas públicas que valorizem seus saberes-fazeres sobre a extração e manejo dos recursos naturais que sejam menos impactantes aos seus ecossistemas.

Sendo assim, a problemática deste estudo gira em torno do seguinte: Quais saberes-fazeres dos extrativistas / agricultores de pequeno porte sobre a extração e manejo dos recursos naturais estão mais alinhados com os princípios ecológicos e com o desenvolvimento rural sustentável das comunidades da Amazônia Atlântica, ou seja, no extremo nordeste paraense, mais especificamente na RESEX marinha Caeté-Taperaçu?

Diante do exposto, esta pesquisa justifica-se como de fundamental importância para salvaguardar os saberes-fazeres destas comunidades rurais que causam menos impacto ambiental, bem como apontar a produção de saberes-fazeres com a lógica da vida no campo, da realidade vivenciada cotidianamente pelos sujeitos, na perspectiva da produção de conhecimentos sobre o campo e sua população.

Por trás desta proposição está também o desafio de se desenvolver uma pesquisa que questiona o paradigma moderno do conhecimento, inserido em um momento histórico de transição para um novo paradigma (pós-moderno) que emerge no horizonte ancorado nos saberes ambientais, na ecologia dos saberes e no paradigma ambiental, aportes teórico-metodológicos propostos por autores como Boaventura de Sousa Santos (2010), Enrique Leff (2006) e Edgar Morin (2005).

Sendo assim, essa pesquisa não trata somente da abordagem dos saberes-fazeres constantes nos cotidianos dos agricultores e extrativistas da RESEX marinha Caeté-Taperaçu, mas também é um estudo sobre o que emerge como conhecimento válido e merecedor de ser reproduzido, contribuindo, dessa forma, para se reconhecer e valorizar identidades profissionais em determinados sentidos, seja histórico, político, cultural e ideológico, dos trabalhadores do campo.

Neste sentido Leff (2006) nos convida a desconstruir os blocos de racionalidades predominantes ancorados na economia e nas tecnologias, alargando a compreensão da realidade sem a visão eurocêntrica e sem pretensões universalistas. Nessa condição, os saberes locais alcançam um estatuto epistêmico que lhes confere reconhecimento na sua singularidade e na sua diversidade. Para o autor:

A racionalidade ambiental indaga assim sobre a fundação do uno e o desconhecimento do outro, que levou ao fundamentalismo de uma unidade universal e à concepção das identidades como mesmidades sem alteridade, exacerbada no processo de globalização no qual irrompe o terrorismo e a crise ambiental como decadência da vida, como vontade de suicídio de ser e extermínio do outro, como a perda de sentidos que acarreta a coisificação do mundo e a mercantilização da natureza (LEFF, 2006, p. 18). 
Além das argumentações supracitadas, pesquisar alternativas ecológicas de desenvolvimento rural tornou-se um imperativo na atualidade, pois problemas de degradação ambiental e a pauperização das áreas rurais atravessam diversas relações sociais tanto em níveis locais e regionais como em níveis nacionais e internacionais.

Por fim, o estudo é reconhecido por estudar os saberes-fazeres de populações usuárias da Reserva Extrativista (RESEX), Marinha Caeté-Taperaçu, destacando-se aqui o conceito de uma RESEX:

Área utilizada por populações extrativistas tradicionais, cuja subsistência baseia-se no extrativismo e, complementarmente, na agricultura de subsistência e na criação de animais de pequeno porte, e tem como objetivos básicos proteger os meios de vida e a cultura dessas populações, e assegurar o uso sustentável dos recursos naturais da unidade (BRASIL, 2000).

Acrescenta-se ainda que o plano de manejo² da RESEX marinha Caeté-Taperaçu, bem como sua estrutura administrativa (Figura 2), apresenta como objetivo o registro dos conhecimentos, saberes, fazeres, e histórico de uso do recurso nas comunidades, estimulando as atividades de pesquisa cientifica sobre os saberes-fazeres como contribuição para o conhecimento, valorização e difusão do modo de vida tradicional dos extrativistas e moradores (ICMBio, 2012).

\footnotetext{
${ }^{2}$ Conforme a Lei no 9.985/2000, que estabelece o Sistema Nacional de Unidades de Conservação, em seu Capítulo I, Art. $2^{\circ}$ - XVII, Plano de Manejo é um documento técnico mediante o qual, com fundamento nos objetivos gerais de uma Unidade de Conservação, se estabelece o seu zoneamento e as normas que devem presidir o uso da área e o manejo dos recursos naturais, inclusive a implantação de estruturas físicas necessárias à gestão da Unidade (Brasil, 2000).
} 


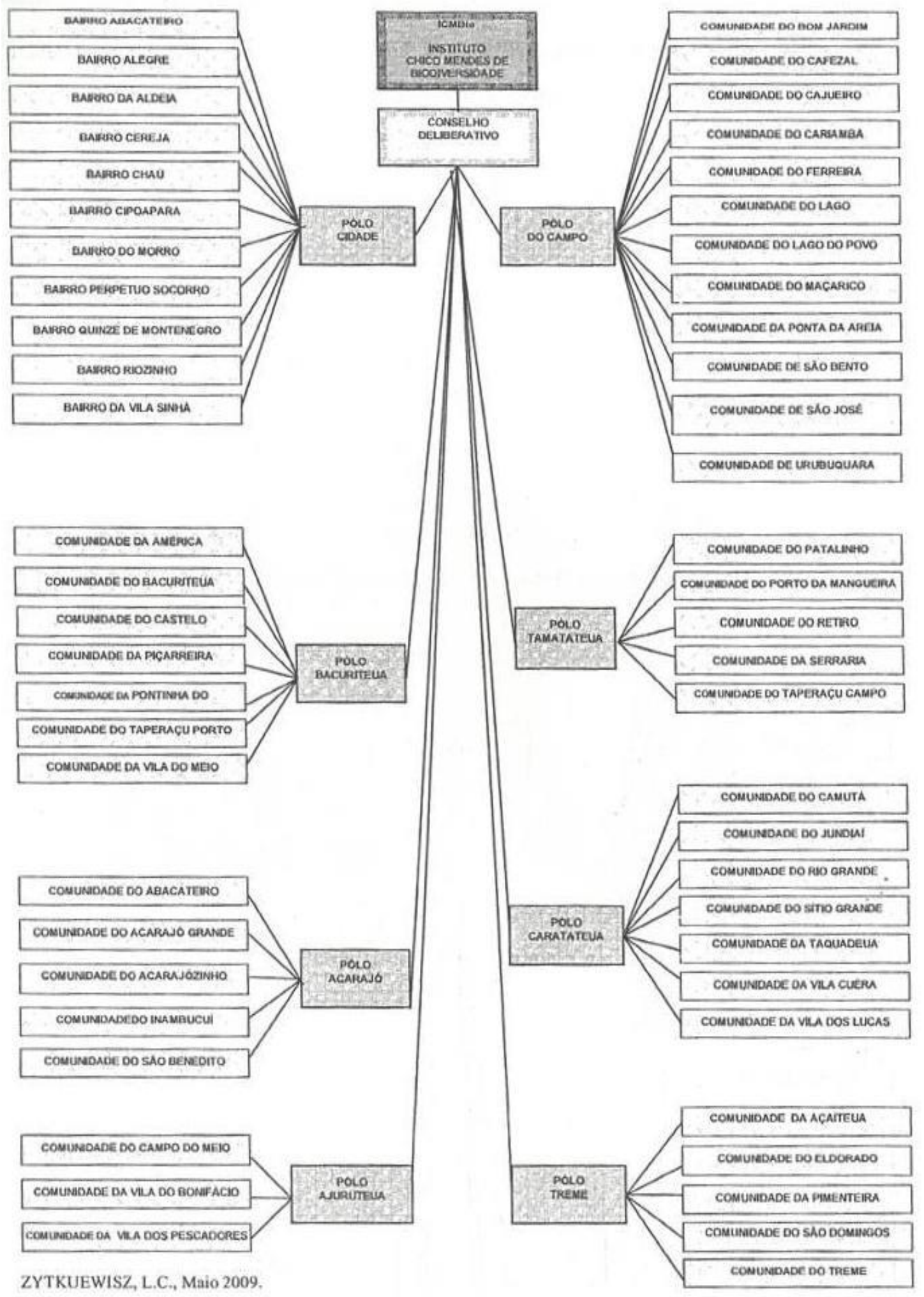

Figura 2: Estrutura da RESEX marinha Caeté-Taperaçu

Fonte: PERES, A. C. Estudo Antropológico de uma Comunidade na Abrangência da Reserva Extrativista Marinha Caeté-Taperaçu (Bragança-Pará-Brasil). Tese. PPGCS da UFPA (Área de Concentração: Antropologia). Belém: UFPA, 2011, p. 36. 


\section{O CAMINHO}

É bom ter em mente que os termos população tradicional, povo tradicional comunidade tradicional, entre outros, não são categorias históricas, um erro causado pela proximidade do termo história com tradição. São, de fato, categorias socioculturais e, principalmente, de cunho político, consolidadas através de estratagemas legais e políticas públicas conquistadas no âmbito dos movimentos de luta pelo direito à terra e ao extrativismo dos recursos naturais (VIANNA, 2008).

Apesar do termo trazer representações sociais das comunidades de RESEX, protegidas e regidas pelo Sistema Nacional de Unidades de Conservação (SNUC), não houve um consenso da exclusividade, pois o conceito abrange muito mais do que moradores da RESEX; populações tradicionais, segundo a SNUC, são "grupos humanos, culturalmente diferenciados, vivendo há no mínimo três gerações em um determinado ecossistema, historicamente reproduzindo seu modo de vida, em estreita dependência do meio natural para sua subsistência e utilizando os recursos naturais de forma sustentável" (BRASIL, 2000).

Mas este conceito não foi sancionado, pois "o conteúdo da disposição é tão abrangente que nela, com pouco esforço de imaginação, caberia toda população do Brasil" (SANTILLI, 2005, p. 126). Nesta confusão conceitual, determinados autores preferem dividir as populações tradicionais em três dimensões: indígenas, mestiços e remanescentes de quilombolas. Aprofundando esta seara, divide-se os mestiços em caboclos (LIMA, 1999) e ribeirinhos, que possuem denominações diversas como, por exemplo, pescadores (SANT' ANA, 2003), agricultores, caçadores, coletores, entre outros. De fato, são categorias tão amplas e de tamanha complexidade principalmente pela similaridade das bases econômicas dessas populações, que são muito semelhantes (OLIVEIRA, 2007).

Uma das principais causas da pauperização dessas comunidades é a profunda crise ecológica gerada pelos atuais modelos produtivos rurais (agropecuários, florestais, pesqueiros e extrativistas), cujas consequências são fenômenos tais como a depredação da terra e dos recursos hídricos, a deflorestação, a salinização, a extinção da flora e da fauna e as mudanças meteorológicas e climáticas locais, regionais, nacionais e globais, estão induzindo mudanças na maneira de enxergar as problemáticas e conceber as investigações científicas, causando a aparição de novos paradigmas metodológicos e teóricos.

Dentro desse contexto, destaca-se uma nova forma de abordar os fenômenos, no sentido de (re)valorizar os saberes-fazeres tradicionais sobre o uso da natureza e resgatar para este cenário o 
protagonismo das comunidades rurais na superação da crise ecológica deflagrada na década de 1970. Esta nova maneira de fazer ciência se chama etnoecologia, que, num sentido mais amplo, esforça-se por retomar as práticas tradicionais de manejo dos recursos naturais como ponto de partida para se desenhar posturas alternativas de produção que sejam ecologicamente viáveis (POSEY, 1984; TOLEDO, 1992).

Sua origem remonta às escolas científicas tão distintas como a etnociência ou a antropologia cognoscitiva e a ecologia cultural dentro da antropologia, a etnoecologia tem ganhado muito espaço no interior da agroecologia (ALTIERI, 1987), cuja ideia central se baseia no fato de o produtor rural tradicional possuir uma determinada racionalidade ecológica, que favorece o uso sustentável dos recursos naturais.

Sendo assim, estabeleceu-se algumas estratégias e procedimentos metodológicos a fim de se alcançar os objetivos traçados, a saber:

\section{INSTRUMENTOS DE PESQUISA NA ETNOECOLOGIA}

Os primeiros contatos com as comunidades foram pautados num roteiro exploratório. Este instrumento foi gerador de mais dois, aplicados no decorrer da segunda fase: um roteiro sobre as relações sociais da família em si (contexto social, econômico e cultural do ser humano), e outro sobre a atividade de extração / manejo dos recursos naturais, saberes-fazeres relacionados a estas atividades em si.

Os dois roteiros passaram por contínuos processos de reestruturação, pois todo roteiro sempre sofrerá influências das pesquisas de campo e das concomitantes análises dos dados. Contudo, houve uma preocupação constante em se manter o foco na temática e no conteúdo do roteiro; portanto, as entrevistas semiestruturadas, fundamentadas nestes roteiros, foram flexíveis, permitindo averiguar pontos que apareceram no decorrer das entrevistas (ALBUQUERQUE \& LUCENA, 2004, p. 39-41).

A intenção desta pesquisa foi e continua sendo realizar as entrevistas de forma oral, mas, dependendo da sensibilidade do entrevistador ou mesmo das escolhas dos entrevistados, é permitido fazer mudanças para o registro escrito. Além das entrevistas, realizam-se, também, registros fotográficos e/ou fílmicos, principalmente nas observações sobre os fazeres propriamente dito.

Como estratégia de realçar a veracidade das informações, segundo Johannes (1981), são realizadas, além do já citado, entrevistas sincrônicas (mesma entrevista com diferentes entrevistados 
simultaneamente) e entrevistas diacrônicas (repetições das perguntas ao mesmo entrevistado, após um considerado intervalo de tempo).

\section{ANÁLISE DOS DADOS}

Constituindo-se de caráter majoritariamente qualitativo, cumpriram, segundo Moraes (1999), 4 etapas distintas:

I. Unitarização, que se resume na transcrição e leitura das entrevistas com o objetivo de captar as unidades de análise, que são pistas-chaves de conteúdo, que ajudarão na construção das categorias de análise;

II. Categorização, que consiste na reunião dos dados por afinidade ou semelhança com o objetivo de formar categorias temáticas;

III. Descrição, que se trata da explanação dos resultados encontrados na pesquisa de campo;

IV. Interpretação, que seria a reflexão e compreensão dos dados descritos por meio do confronto com o conhecimento científico.

Destaca-se o cuidado de, ao se interpretar os dados explanados, termos usado o procedimento da "cognição comparada" (MARQUES, 1991, 2001), onde os dados obtidos em campo são comparados com as informações acadêmicas, podendo confirmá-las, complementá-las ou contrariá-las; caso sejam contrariadas, é o momento de se retomar a discussão científica, ou seja, o saber popular / tradicional gera novos conhecimentos científicos. Dessa forma, conhecimento popular e científico interagem, ocasionando uma integração entre ambos, ou seja, um complementa o outro, como de fato ocorreu em nossa pesquisa.

\section{A EDUCAÇÃO INFORMAL DO CAMPO}

Quando se fala em "Educação do Campo", há uma tendência de se reverenciar a Educação oficial do Campo, a escolarizada, a institucionalizada, esquecendo-se muitas das vezes que a educação do campo se dá de forma informal, no dia-a-dia, no cotidiano, nas relações entre os membros da família e da comunidade onde estão inseridos. Vale ressaltar que o melhor seria falarmos em "Educação dos Campos", no sentido plural da palavra, pois existem muitos campos, 
mangues, rios, solos, terras, etc. Afinal, "Educação do Campo" é um conceito historicamente construído,

que já pode configurar-se como uma consciência de mudança, como uma categoria de análise da situação ou das práticas e políticas de educação dos trabalhadores do campo. Há práticas sociais, políticas que configuram essa categoria de análise - Educação do Campo e que tem como sujeitos, protagonistas os movimentos sociais camponeses. Uma prática social ainda em processo de construção histórica (ARROYO, 2015, p. 49).

Vale destacar, também, que a categoria "Campo" aqui definida é uma superação da categoria "rural", que muitas das vezes esteve ligada à atividade da agricultura. "Campo" não significa aqui apenas um território de produção agrícola, mas sim um espaço em que sujeitos diversos e suas inúmeras relações socioculturais, com distintas racionalidades (MOREIRA, 2007).

Seja nos mangues, na catação de caranguejos, seja na produção de farinha, seja na pesca artesanal, seja nas pescas de curral, seja na extração do açaí ou do buriti, a socialização destes saberes-fazeres se dá nos próprios espaços de produção e/ou extração dos recursos necessários para a vivência do homem e da mulher do campo. Estes sujeitos participam de uma educação informal do campo ao "incorporarem seus domínios pessoais de interações de e entre afetos, sensações, sentidos ou saberes" (BRANDÃO, 2002, p. 26).

Mas, nas estratégias de ensinagens e aprendizagens dos saberes-fazeres tradicionais, o processo de produção e/ou extração de um determinado recurso vai se dando aos poucos, de geração para geração, de pai e/ou mãe para filho e/ou filha, dos mais velhos para os mais novos, das atividades mais simples para as atividades de mais complexidade.

A avaliação também é feita pelos mais velhos, aqueles que geralmente gestam as etapas das atividades de extração e/ou produção dos recursos, afinal

\footnotetext{
"não é possível praticar sem avaliar a prática. Avaliar a prática é analisar o que se faz, comparando os resultados obtidos com as finalidades que procuramos alcançar com a prática. A avaliação da prática revela acertos, erros e imprecisões. A avaliação corrige a prática, melhora a prática, aumenta a nossa eficiência. $\mathrm{O}$ trabalho de avaliar a prática jamais deixa de acompanhá-la" (FREIRE, 1994, p. 92).
}

Com relação aos conteúdos dessa educação informal do campo, sob a perspectiva da abordagem etnoecológica, percebe-se que os conhecimentos tecnológicos (tanto nos aspecto sociais e culturais como nos aspectos políticos e econômicos) advindos dos saberes tradicionais dos extrativistas / agricultores de pequeno porte sobre a extração e manejo dos recursos naturais que estão mais alinhados com os princípios ecológicos e com o desenvolvimento rural sustentável podem contribuir para uma saída da crise ecológica e humanitária que se instalou no planeta, como, 
por exemplo, nas diferentes técnicas, seja na escolha das variedades de mandioca, seja nas metodologias dos cultivos, seja no processamento da mandioca e produção da farinha, incluindo neste último o destino da biomassa não comestível, ou seja, a dimensão ecológica da pesquisa etnográfica, aproximando-se da denominada etnoecologia, ilustrada na Figura 3:
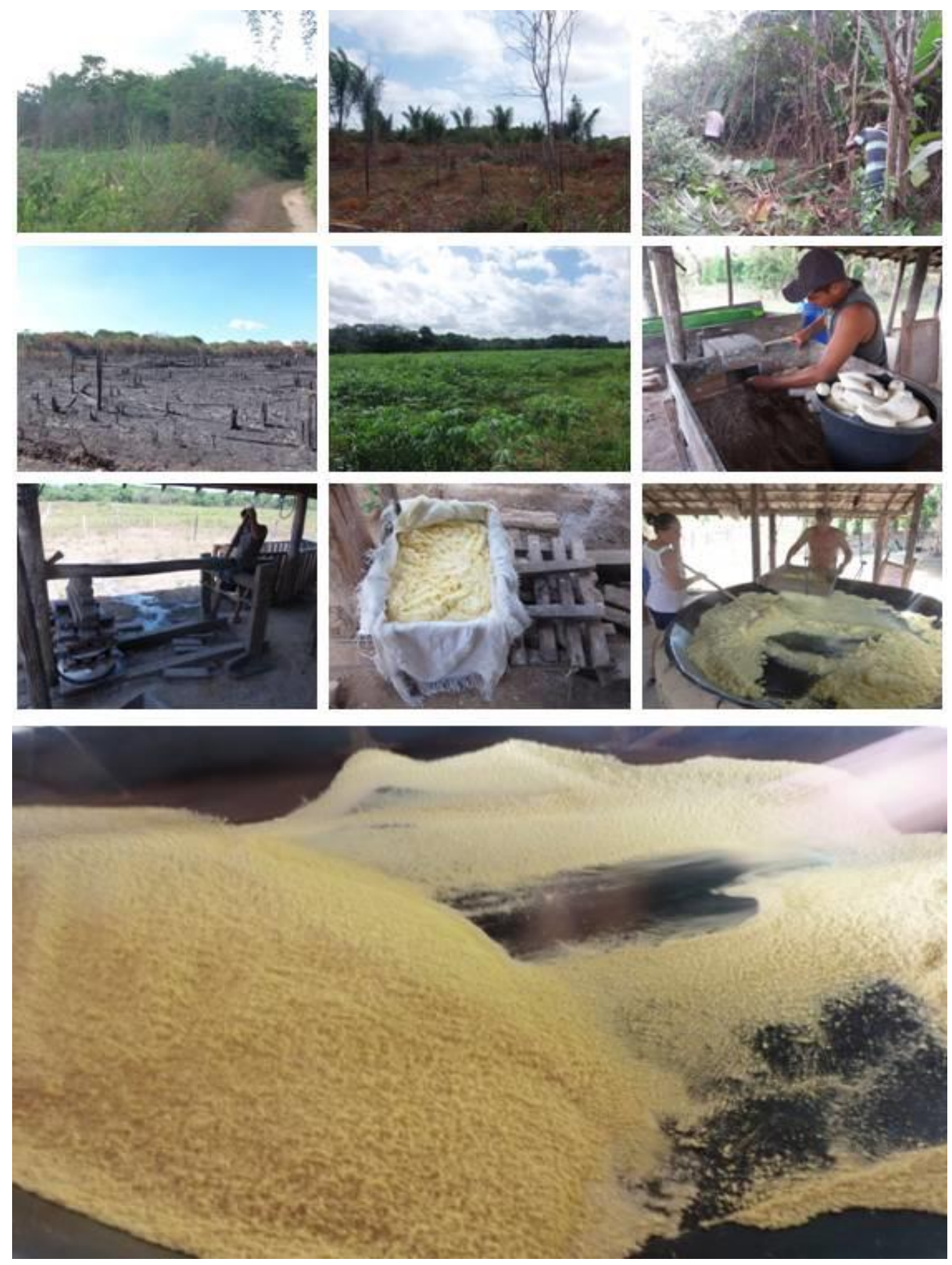

Figura 3: Registros fotográficos das etapas da produção de farinha. Fonte: Acervo do autor. 
Registraram-se, também, diferentes tecnologias que se fazem presentes nos saberes tradicionais que possam compor um leque de novas possibilidades e, quiçá, novas racionalidades para o paradoxal desenvolvimento sustentável, como as constantes na Figura 4.
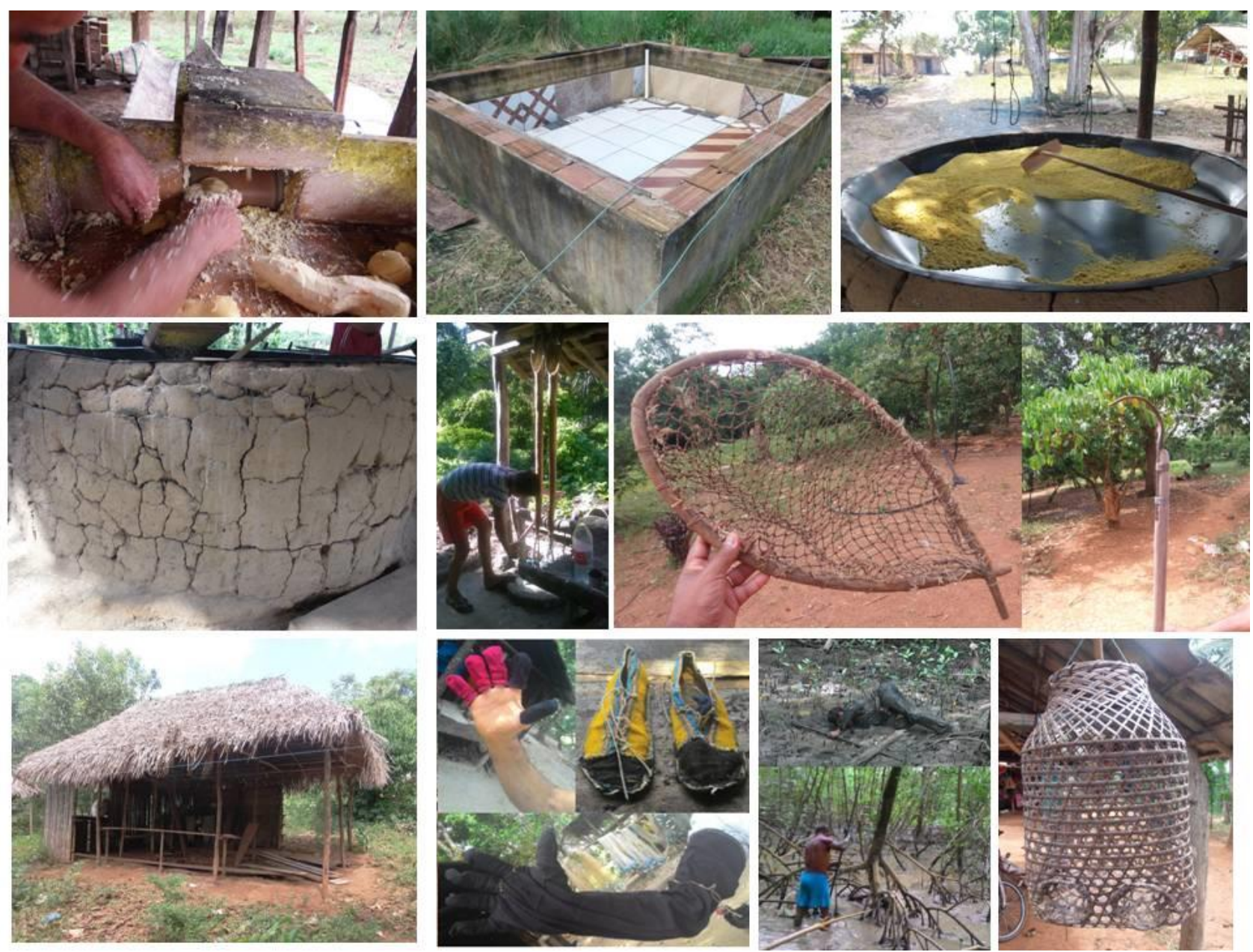

Figura 4: Tecnologias advindas dos Saberes Tradicionais dos habitantes da RESEX Marinha Caeté-Taperaçu Fonte: Acervo do autor.

Ademais, Constatou-se que os saberes-fazeres, além de estruturarem os espaços internos da RESEX Marinha Caeté-Taperaçu. Tais espaços são concretizados por saberes-fazeres que fazem parte do cotidiano dos habitantes da RESEX. A socialização de tais saberes-fazeres se dá, por meio da educação informal.

Observou-se que os produtos advindos destes saberes-fazeres culminam em trocas, ritual cultural no qual as famílias buscam garantir sua soberania alimentar, transformando estes momentos em encontros de interações e trocas não só de produtos mas também de saberes-fazeres. 
Apesar dos saberes-fazeres requererem a participação coletiva, é ínfimo o capital social da RESEX em questão. Além da fala de participação na gestão da RESEX, que, em tese, deveria ser compartilhada, fica concentrada nas mãos de poucos, materializados na Associação dos Usuários da RESEX Marinha Caeté-Taperaçu (ASSUREMACATA). Este fato tende a anular a participação dos comunitários nas políticas decisórias relacionadas ao cotidiano da RESEX.

Seja como for, o modelo de gestão proposto para as Unidades de Conservação, onde se inclui a RESEX Caeté-Taperaçu, exige a participação da coletividade não apenas nos saberesfazeres, mas também na política decisória de sua ocupação, uso e manejo, sendo decisiva a incursão do poder público para implementar tal perspectiva; caso contrário, a sustentabilidade nesta RESEX estará por um fio.

\section{REFERÊNCIAS}

ALBUQUERQUE, U. P; LUCENA, R. F. P. Métodos e técnicas para coleta de dados. In: ALBUQUERQUE, U. P.; LUCENA, R. F. P. (Org.). Métodos e técnicas na pesquisa etnobotânica. Recife: Livro Rápido / NUPEEA, 2004, p. 37-62.

ALTIERI, M. Agroecology: scientific basis for an alternative agriculture. Westview Press, 1987.

ARROYO, M. G. Os Movimentos Sociais e a construção de outros currículos. In: Educar em Revista, $\mathbf{n}^{\mathbf{0}}$ 55, jan./marc. 2015. Curitiba: Editora UFPR, 2015, pp. 47-68.

BRANDÃO, Carlos Rodrigues. A Educação como Cultura. Campinas - São Paulo: Mercado da Letras, 2002.

BRASIL. Lei $\mathbf{N}^{\mathbf{9}} \mathbf{9 . 9 8 5}$, de 18 de julho de 2000. Disponível em: <http://www.planalto.gov.br/ccivil_03/Leis/L9985.htm>. Último acesso em 15/03/2016.

BRASIL. Decreto de Criação da Reserva Extrativista Marinha Caeté-Taperaçu, de 20 de maio de 2005. Disponível em: <http://www.icmbio.gov.br/brasil/PA/reserva-extrativista-marinha-decaete-taperacu/downloads/decreto-de-20-de-maio-de-2005> . Último acesso em 14/03/2016.

CURY, Carlos Jamil. Educação e contradição. 6.ed. São Paulo: Cortez, 1995.

FREIRE, Paulo. A importância do ato de ler em três artigos que se completam. São Paulo: Cortez, 1984.

GADOTTI, Moacir. A questão da educação formal/ não-formal. In: Anais do INSTITUT INTERNATIONAL DES DROITS DE L'ENFANT (IDE) - Droit à l'éducation: solution à tous les problèmes ou problème sans solution? Sion (Suisse), 18 au 22 octobre 2005. 
GIUSTA, Agnela da Silva. Concepções de Aprendizagens e Práticas Pedagógicas. In: Revista Educ. Ver., Belo Horizonte, jul. 1985. P. 24 -31.

HEBETTE. J.; FREITAS, M. Mudanças tecnológicas na pequena produção agrícola paraense; relatório. Belém: UFPA, 1986.

IBAMA. Relatório do Grupo Permanente de Estudos (GPE) do caranguejo-uçá, realizado no período de 17 a 20/12/91, em Fortaleza- CE. Coleção Meio Ambiente. Série Estudos- Pesca, Brasília. Instituto Brasileiro do Meio Ambiente e Recursos Naturais Renováveis - CEPENE, 1994, p. 107-140.

IBGE - Fundação Instituto Brasileiro de Geografia e Estatística. Disponível em: <www.cidades.ibge.gov.br/xtras/home.php> (Acesso em 06 jun 2015)

ICMBio. Plano de manejo da reserva extrativista marinha de Caeté-Taperaçu (PA).volume II : Planejamento. 2012. p. 175.

JOHANNES, R. E. Working with fishermen to improve coastal tropical fisheries and resource management. Bull. Mar. Sci. 31 (3), 1981, p. 673-680, 1981.

KATO, Maria do Socorro Andrade et al Sistemas de Produção de pequenos produtores de mandioca no município de Bragança - PA. Belém: EMBRAPA, 1992.

LEFF, Enrique. Racionalidade Ambiental - a reapropriação social da natureza. Rio de Janeiro: Civilização Brasileira. 2006.

LIBÂNEO, José Carlos. Pedagogia e pedagogos, para quê? 9.ed. São Paulo: Cortez, 2007.

LIMA, D. M. A construção histórica do termo caboclo. Sobre estruturas e representações sociais no meio rural amazônico. Novos cadernos NAEA, vol. 2, n. 2 - dezembro de 1999.

MARQUES, José Geraldo W. Pescando pescadores: ciência e etnociência em uma perspectiva ecológica. 2.ed. São Paulo: Núcleo de apoio à pesquisa sobre populações humanas e áreas úmidas brasileiras, USP, 2001.

MARQUES, José Geraldo W. Aspectos ecológicos na etnoictiologia dos pescadores do complexo estuarino-lagunar Mundaú-Manguaba, Alagoas. Tese (Doutorado em Ciências) - Curso de PósGraduação em Ecologia, Universidade Estadual de Campinas, Campinas, 1991.

Ministério do Meio Ambiente (MMA). MMA lança projeto para conservação de manguezais. Publicação em 07/02/2006. Disponível em: < http://www.mma.gov.br/informma/item/3033-mmalanca-projeto-para-conservacao-dos-manguezais > Acesso em 22 de ago. 2016.

MORAES, Roque. Análise de conteúdo. In: Educação XXII (37), 1999, p. 7-32.

MOREIRA, José Roberto. Terra, poder e território. São Paulo: Expressão Popular, 2007. 
MORIN, Edgar. Introdução ao Pensamento Complexo. Porto Alegre: Sulina, 2005.

OLIVEIRA, Euzébio de. Caracterização socioambiental das comunidades de Tamatateua e Acarajó, nordeste do Pará: Contribuição para a gestão integrada na RESEX Marinha CaetéTaperaçú. Dissertação de Mestrado em Ecologia de Ecossistemas Costeiros e Estuarinos. Bragança, PA: Universidade Federal do Pará (Campus de Bragança), 2007.

PERES, A. C. A comunidade zooplanctônica em um canal de maré no estuário do rio Caeté, Bragança (Pará, Brasil). Dissertação de Mestrado. Programa de Pós-Graduação em Zoologia, Universidade Federal do Pará, Belém, Brasil, 1999.

POLITY, Elizabeth. Dificuldade de Ensinagem: Que história é essa...? São Paulo: Vetor, 2002.

POSEY, D. A. et al. Ethnoecology as applied anthropology in Amazonian development. In: Human Organization, $n^{\circ}$ 43, p. 95-107, 1984.

SANT'ANNA, R. Populações Humanas em Unidades de Conservação. In: ESTERCI, N.; LIMA, D.; LÉNA, P. (Eds.). Dinâmicas de ocupação e de exploração-efeitos e respostas sócio-culturais. Boletim Rede Amazônia. Ano 2. No 1. 2003.

SANTILLI, Juliana. Socioambientalismo e novos direitos - Proteção jurídica à diversidade biológica e cultural. São Paulo: Petrópolis. 2005.

SANTOS, Boaventura de Sousa. Para além do pensamento abissal: das linhas globais a uma ecologia dos saberes. In SANTOS, B. S.; MENESES, M. P. Epistemologias do Sul. São Paulo: Cortez, 2010, p. 31-83.

SANTOS, Marcos Ronielly da Silva; SOUSA JÚNIOR, Clóvis Nivaldo da Costa. Caracterização Ambiental dos Recursos Hídricos no Município de Bragança. Pará. Bragança: IFPA, 2012.

SANTOS, Rita de Cássia P. dos; LISBOA, Regina C. L. MUSGOS (BRYOPHYTA) DO NORDESTE PARAENSE, BRASIL- 1. ZONA BRAGANTINA, MICRORREGIÃO DO SALGADO E MUNICÍPIO DE VISEU. In: ACTA AMAZÔNICA 33(3): 415-422. Disponível em <http://www.scielo.br/pdf/aa/v33n3/v33n3a07>. Acessado em 02/02/2016.

SOUSA JÚNIOR, Clóvis Nivaldo da Costa. A Inserção de Conhecimentos Populares no Ensino da Biologia. Bragança: UFPA, 2010.

TOLEDO, Victor. M. What is Ethnoecology? Origins, scope and implications of a rising discipline. In: Etnoecológica 1 (1), p. 05-21, 1992.

VIANNA, L. P. De invisíveis a protagonistas - Populações tradicionais e unidades de conservação. Editora: Annablume. 2008. 